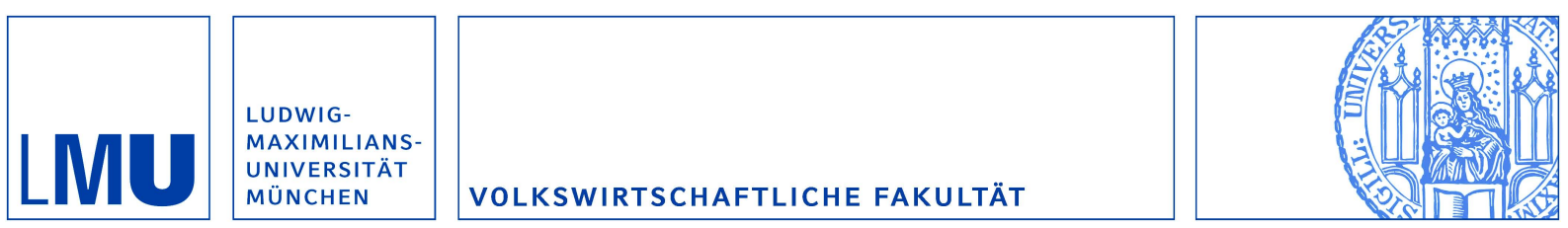

Irlacher, Michael und Unger, Florian:

Effective tax rates, endogenous mark-ups and heterogeneous firms

Munich Discussion Paper No. 2018-6

Department of Economics

University of Munich

Volkswirtschaftliche Fakultät

Ludwig-Maximilians-Universitäł München

Online at https://doi.org/10.5282/ubm/epub.49717 


\title{
Effective tax rates, endogenous mark-ups and heterogeneous firms*
}

\author{
Michael Irlacher \\ University of Munich ${ }^{\dagger}$
}

\author{
Florian Unger \\ University of Munich ${ }^{\ddagger}$
}

May 24, 2018

\begin{abstract}
We provide a new explanation why effective tax rates are smaller for larger firms even in the absence of common channels like profit shifting and lobbying. This result emerges in a heterogeneous firms model with endogenous mark-ups. Our framework features imperfect tax pass-through into prices and partial deductibility of production costs. Corporate taxes reduce mark-ups and hence pre-tax profits, especially for high cost firms. As production costs are only partially deductible, high cost producers are affected most by taxes. We further show that shocks which affect mark-ups through competition, like globalization, reinforce the heterogeneity in effective tax rates across firms.
\end{abstract}

Keywords: Heterogeneous firms, Corporate taxation, Effective tax rate, Linear demand, Endogenous mark-ups

JEL Classification: H25, F12, L11

${ }^{*}$ We thank the German Science Foundation for financial support through CRC TRR 190 and DFG grant number EC 216/7-1.

${ }^{\dagger}$ Department of Economics, D-80539 Munich, Germany; e-mail: michael.irlacher@econ.lmu.de

${ }_{\ddagger}^{\ddagger}$ Department of Economics, D-80539 Munich, Germany; e-mail: florian.unger@econ.lmu.de 


\section{Introduction}

There is an ongoing and controversial public debate on the relatively low tax payments of large companies. In the period 2008-2015, the statutory corporate tax rate in the US was 35 percent. However, the most profitable companies out of the Fortune 500 paid on average an effective tax rate of only 21.2 percent on their profits (Institute on Taxation and Economic Policy, 2017). Typical explanations for this observation are profit shifting of large multinational firms (Desai et al. , 2006; Gumpert et al. , 2016; Davies et al. , 2018) and better coordinated lobbying activities (Bombardini, 2008; Richter et al. , 2009).

In this paper, we provide a new explanation why the ratio of tax payments to pre-tax profits (the effective tax rate) is smaller for larger firms. We show that this result can even emerge in a closed-economy framework without profit-shifting or lobbying activities. All we need for our argument is that mark-ups are endogenous and production costs are only partially tax deductible. While existing studies explain lower effective tax rates of large firms by legal or even illegal tax evasion, our study ties this fact to the underlying demand structure in the market. To the best of our knowledge this explanation for low tax payments of large firms is novel. We argue that this channel should be taken into account in empirical research and in the debate on policy measures addressing tax evasion.

To derive our results, we introduce tax policy in a general equilibrium model with firm heterogeneity and endogenous mark-ups following Melitz \& Ottaviano (2008). Tax policy is determined by two instruments: a tax rate on profits and a share of production costs that is tax deductible. These measures have been used in recent tax-rate-cut-cum-base-broadening reforms. ${ }^{1}$ In our framework with linear demand, corporate tax rates reduce mark-ups and hence pre-tax profits which holds in particular for high cost firms. At the same time, these firms can only deduct a fraction of their large production costs. As a consequence, the ratio of tax payments to pre-tax profits is larger compared to low cost firms even in the absence of common explanations such as profit shifting or lobbying. Interestingly, our model is also able to provide a rationale for a positive relation between firm size and effective tax payments as found in some empirical studies. This case occurs if production costs are subsidized by the government.

Importantly, this result hinges on the demand structure that features endogenous markups. Empirical evidence shows indeed that more productive firms charge higher mark-ups (De Loecker \& Warzynski, 2012; Bellone et al. , 2016). However, the existing literature on firm heterogeneity and corporate taxation typically builds on CES preferences. In such a

\footnotetext{
${ }^{1}$ For the OECD countries, the average statutory corporate tax rate has fallen from $39.9 \%$ in 1990 to $27.5 \%$ in 2014 (Haufler \& Langenmayr, 2015). At the same time, broadening of tax bases has led to an increase of tax revenues despite of lower tax rates.
} 
framework prices are set as a constant mark-up over marginal costs and our result would not emerge as firms perfectly pass on taxes to consumers: a 1\% increase of the corporate tax rate leads to a $1 \%$ increase in prices. ${ }^{2}$ In our model with linear demand, there is only imperfect pass-through of taxes into prices which reduces mark-ups. As high cost firms face more price sensitive consumers they respond stronger to changes in tax policy. Consequently, the tax burden relative to pre-tax profits increases more for small firms with lower productivity.

In the public debate, globalization is perceived as an important driving force for the heterogeneity in effective tax rates across firms as it facilitates profit-shifting of large companies. We provide a new explanation for this observation by showing how general equilibrium effects change the effective tax payments of heterogeneous firms. Shocks which affect mark-ups through the toughness of competition, such as trade liberalization, reinforce the heterogeneity in relative tax payments across firms. The reason behind this result is that a larger market enhances firm entry which at the same time increases competition and hence, compresses mark-ups in particular for small firms.

Our paper is related to recent research that analyzes tax competition for internationally mobile firms that differ in their productivity (Baldwin \& Okubo, 2009; Davies \& Eckel, 2010; Krautheim \& Schmidt-Eisenlohr, 2011; Haufler \& Stähler, 2013). The focus of these papers is to explain how countries of varying size optimally set tax policy and how heterogeneous firms select into these countries. Related to our paper, Bauer \& Langenmayr (2013) provide a different rationale for the fact that large multinational firms pay relatively low taxes. They show that profit taxation under the ruling arm's length principle allows most productive firms to shift profits abroad even under full compliance with the tax code. In contrast, we show that the relatively low effective tax rates of large firms can be explained even in a closed-economy setting without profit shifting. Bauer et al. (2014) show that endogenous tax policy in a model with firm heterogeneity represents an additional adjustment to trade liberalization. In contrast to our work, this literature typically builds on a CES demand structure and hence, does not capture our result which requires mark-ups to be firm-specific and endogenous. ${ }^{3}$ Egger et al. (2018) highlight an alternative explanation for low effective tax rates of large multinationals that can threat to relocate production which increases their bargaining power with tax authorities.

Our paper is also related to empirical studies on the relation between the effective tax rate and firm size. In a recent survey, Belz et al. (2018) document conflicting results on this relationship. Following the accounting literature, there are two competing theories that

\footnotetext{
${ }^{2}$ In a broader sense, our paper is related to a growing literature on mark-ups and cost pass through into prices (Weyl \& Fabinger, 2013; Mrázová \& Neary, 2017).

${ }^{3}$ In the Appendix, we show that the ratio of tax payments to pre-tax profits is constant across firms in a framework with CES preferences.
} 
explain this ambiguity. The political power theory assumes that larger firms have more resources to influence policy making in their favor which implies a lower effective tax rate for large firms. In contrast, the political cost theory states that large companies face stronger exposure to regulations which leads to a positive relation between firm size and the effective tax rate. We contribute to this literature by adding an alternative explanation which arises from the interaction of the tax system and the market structure.

\section{The model}

We introduce corporate taxes in a general equilibrium model with heterogeneous firms that follows the lines of Melitz \& Ottaviano (2008). Importantly, our model features linear demand leading to endogenous mark-ups. Throughout our study, we highlight novel results that are specific to the demand system and contrast them to an alternative framework with CES preferences where mark-ups would be constant (see Appendix).

In a first step, we introduce tax policy which is determined by two instruments: a tax rate on profits and a share of production costs that is tax deductible. Following this, we derive consumer demand and optimal firm behavior to finally characterize a free entry equilibrium. This setting allows us to derive our main result which shows relative tax payments as a function of firm productivity. Moreover, we conduct comparative static exercises with respect to changes in tax policy as well as globalization, and analyze the effects on the effective tax rate at the firm level.

\subsection{Consumers}

We consider an economy that is endowed with $L$ consumers each holding one unit of capital which is the sole production factor. Consumers maximize utility over a continuum of differentiated varieties indexed by $i \in \Omega$, and a homogenous outside good $q_{0}^{c}$ which is chosen as numeraire. The utility is given by: ${ }^{4}$

$$
U=q_{0}^{c}+\alpha \int_{i \in \Omega} q_{i}^{c} d i-\frac{1}{2} \gamma \int_{i \in \Omega}\left(q_{i}^{c}\right)^{2} d i-\frac{1}{2} \eta\left(\int_{i \in \Omega} q_{i}^{c} d i\right)^{2} .
$$

The parameter $\gamma$ indexes the degree of product differentiation between the varieties. The extreme case of $\gamma=0$ implies that products are perfectly substitutable and hence, consumers only care about their total level of consumption given by $Q^{c}=\int_{i \in \Omega} q_{i}^{c} d i$. Moreover, $\alpha$ and

\footnotetext{
${ }^{4}$ The quadratic preferences give rise to a linear demand function and were first developed in Ottaviano et al. (2002). In the context of tax competition with homogeneous firms it was used in Ottaviano \& van Ypersele (2005).
} 
$\eta$ determine the substitutability between the outside good and the differentiated varieties. Utility maximization of Eq. (1) subject to the budget constraint leads to the following linear inverse demand function:

$$
p_{i}=\alpha-\gamma q_{i}^{c}-\eta Q^{c}
$$

In a next step, we derive direct market demand $q_{i}$ by aggregating demand of $L$ consumers:

$$
q_{i}=\frac{\alpha L}{(\gamma+\eta N)}-\frac{L}{\gamma} p_{i}+\frac{\eta N}{\gamma+\eta N} \frac{L}{\gamma} \bar{p} .
$$

We define $\Omega^{*} \subset \Omega$ as the subset of varieties that are actually consumed (i.e. $q_{i}>0$ ). This subset consists of a total number of $N$ varieties whose average price is given by $\bar{p}=$ $(1 / N) \int_{i \in \Omega^{*}} p_{i} d i$. Inspection of Eq. (3) shows that demand for variety $i$ falls to zero if

$$
p_{i}=p^{\max }=\frac{1}{(\gamma+\eta N)}(\alpha \gamma+\eta N \bar{p})
$$

This is an important difference to CES demand systems and implies that the price elasticity of demand $\varepsilon_{i} \equiv \frac{\partial q_{i}}{\partial p_{i}} \frac{p_{i}}{q_{i}}=\left(\frac{p^{\max }}{p_{i}}-1\right)^{-1}$ is not constant and is not uniquely determined by the degree of product differentiation $\gamma$. Eq. (4) shows that tougher competition (increase in $N$ or decrease in $\bar{p}$ ) increases the price elasticity for a given price level $p_{i}$.

\subsection{Firm behavior}

Producing one unit of the numeraire good $q_{0}$ requires one unit of capital as an input. We assume that the market for this good is perfectly competitive and it is sold at a price $p_{0}=1$. These assumptions fix the returns to capital to unity. The differentiated sector is characterized by monopolistic competition. Firms pay fixed costs $f_{E}$ to enter the market and draw marginal costs $c$ from a distribution $G(c)$ with support on $\left[0, c_{M}\right]$. Hence, the productivity of a firm is determined by $\frac{1}{c}$. Firms only learn about their cost level after incurring the fixed entry costs. Given that the payment of $f_{E}$ is sunk, all firms that can cover their marginal cost and generate positive after-tax profits survive and produce.

Before we derive optimal firm behavior, we characterize the tax system in the economy. We follow Bauer et al. (2014) and assume that the government has two policy instruments: i) the tax rate $t$ and ii) a tax deductibility parameter $\beta<1$. The latter determines the tax base which is given by the firm's revenue less a tax-deductible share $\beta$ of the variable production costs. We assume that tax revenues are redistributed to consumers. ${ }^{5}$ Given this

\footnotetext{
${ }^{5}$ Because of the assumption of quasi-linear preferences, all income effects are absorbed by the outside sector. Hence, the redistribution of tax revenues has no impact on the consumption of differentiated varieties.
} 
tax regime, the after-tax profits $\pi(c)$ of a firm with cost draw $c$ are given by

$$
\pi(c)=\underbrace{(p(c)-c) q(c)}_{\text {Pre-tax profits }}-t \underbrace{(p(c)-\beta c) q(c)}_{\text {Tax base }} .
$$

We rewrite Eq. (5) as follows:

$$
\pi(c)=(1-t)[p(c)-\Psi c] q(c)
$$

where we denote $\Psi=\frac{(1-t \beta)}{(1-t)}$ as the tax factor. Throughout our analysis, we assume a partial deductibility of production costs $\beta<1$ implying that the tax factor is larger than one and rises in the corporate tax rate. Eq. (6) shows that the tax factor $\Psi$ enters multiplicative with production costs and hence, represents the effective cost of capital in our framework. ${ }^{6}$ In this case, tax policy has allocative consequences. Note that $\beta>1$ would imply that production costs are subsidized by the government such that $\Psi<1$. $^{7}$ We will also discuss the implications of this case below.

Given the existence of a choke price $p^{\max }$, all firms with effective costs $\Psi c$ larger than $p^{\text {max }}$ have to exit the market. ${ }^{8}$ We denote $c_{D}$ as the cost draw of a firm that just breaks even and is indifferent between serving or exiting the market, i.e. $p^{\max }=\Psi c_{D} \cdot{ }^{9}$ Following the analysis of Melitz \& Ottaviano (2008), all firm performance measures can now be written as a function of the cost draw $c$ and the cost cutoff $c_{D}$. Importantly, the latter variable is determined endogenously in general equilibrium and depends both on the average price $\bar{p}$ as well as the number of firms $N$ in the economy. Firm performance measures are given by:

$$
\begin{gathered}
p(c)=\frac{\Psi}{2}\left(c_{D}+c\right), \\
\mu(c)=\frac{\Psi}{2}\left(c_{D}-c\right), \\
q(c)=\frac{L \Psi}{2 \gamma}\left(c_{D}-c\right), \\
\pi(c)=(1-t) \frac{L \Psi^{2}}{4 \gamma}\left(c_{D}-c\right)^{2},
\end{gathered}
$$

\footnotetext{
${ }^{6}$ Remember that the returns to capital are exogenous due to the existence of the outside sector and are equal to unity.

${ }^{7}$ Throughout our analysis we assume parameter values such that $\Psi>0$.

${ }^{8}$ In comparison to frameworks with CES preferences (e.g. Melitz, 2003) there is no need for any fixed costs to derive firm exits.

${ }^{9}$ The underlying assumption is that $c_{M}>c_{D}$ which implies that some firms are exiters.
} 
whereas $\mu(c)=p(c)-\Psi c$ denotes the mark-up of a firm with cost $c$.

More productive firms set lower prices and earn higher revenues as well as profits than less productive firms. Importantly, and in contrast to a framework with CES preferences, more productive firms do not pass on all of their lower production costs to consumers but set higher mark-ups than firms with higher costs. Firm performance measures in Eqs. (7)-(10) are affected by tax policy in two ways: i) a direct effect through $\Psi$ and ii) an indirect effect via changes of the cost cutoff $c_{D}$. We discuss these general equilibrium effects in the next section.

\subsection{Free entry and equilibrium}

The equilibrium is determined by two conditions. Following Eq. (4), the zero profit condition relates the cost cutoff $c_{D}=\frac{p^{\max }}{\Psi}$ to the endogenous number of firms and is given by:

$$
c_{D}=\frac{1}{\Psi(\gamma+\eta N)}(\alpha \gamma+\eta N \bar{p}),
$$

whereas the average price is $\bar{p}=\frac{1}{N} \int_{0}^{c_{D}} p d i=\Psi \frac{c_{D}+\bar{c}}{2}$, and average costs can be written as $\bar{c}=\frac{1}{G\left(c_{D}\right)} \int_{0}^{c_{D}} c d G(c)$. Rearranging Eq. (11) allows us to write the number of available varieties as a function of the cost cutoff $c_{D}$ :

$$
N=\frac{2 \gamma\left(\alpha-\Psi c_{D}\right)}{\Psi \eta\left(c_{D}-\bar{c}\right)}
$$

At the entry stage, firms pay fixed entry costs $f_{E}$ and draw a cost parameter $c$ from the distribution $G(c)$. We assume that a fraction $\beta$ of entry costs is tax deductible. Free entry ensures that expected after-tax profits are equal to the non-deductible part of fixed entry costs which leads to a second condition:

$$
\int_{0}^{c_{D}} \pi(c) d G(c)=(1-t \beta) f_{E}
$$

To solve our model, we assume that productivity draws $\frac{1}{c}$ follow a Pareto distribution on [0, $\left.c_{M}\right]$. We use the following parameterization $G(c)=\left(\frac{c}{c_{M}}\right)^{k}$ where $k \geq 1$ denotes the shape parameter of the distribution. This allows us to explicitly solve Eq. (13) for the cost cutoff:

$$
c_{D}=\left(\frac{\gamma \phi}{L \Psi}\right)^{\frac{1}{2+k}}
$$


with $\phi=2(k+1)(k+2)\left(c_{M}\right)^{k} f_{E}$. A higher tax factor $\Psi$ clearly reduces $c_{D}$, as effective marginal production costs increase, which forces the least productive firms to exit:

$$
\frac{\partial c_{D}}{\partial \Psi}=-\frac{\gamma \phi}{L \Psi^{2}(2+k) c_{D}^{1+k}}<0
$$

Hence, we observe that an increase in the tax factor affects high cost firms more than low costs firms. The reason is that consumers of high cost varieties react more price sensitive than consumers of low cost varieties. This implies that following an increase in the tax factor high cost producers have to restrict mark-ups and quantities more than low cost producers. This can be seen by the derivative of Eq. (9):

$$
\frac{d q(c)}{d \Psi}=\frac{L}{2 \gamma}\left(c_{D}-c\right)+\frac{L \Psi}{2 \gamma} \frac{\partial c_{D}}{\partial \Psi} .
$$

The first term in Eq. (16) is positive and increases in the cost difference relative to the marginal producer in the market. As firms exit, the number of varieties in Eq.(12) decreases and competition is reduced. Hence, market shares are reallocated towards remaining producers. The second effect is negative and shows the decrease in the cost cutoff as discussed above. For the firm with cost draw $c^{*}=\frac{1+k}{2+k} c_{D}$ the two effects exactly offset each other, i.e. all firms with $c<c^{*}\left(c>c^{*}\right)$ expand (reduce) outputs. For the marginal firm with $c=c_{D}$ only the second effect occurs. The same intuition holds for mark-ups and profits. These results will be central for the main implications of our study.

\subsection{Tax payments of heterogeneous firms}

In this section, we derive the effective tax rate to address the observed pattern that large firms pay relatively low taxes. Common explanations for this fact include profit shifting of large multinational firms (Desai et al. , 2006; Gumpert et al. , 2016; Davies et al. , 2018) and better coordinated lobbying activities (Bombardini, 2008; Richter et al. , 2009). In our framework, we show that the result of relatively low tax payments of large firms arises even in a closed economy setting without multinational firms and in the absence of lobbying. As we will argue in the following, the reason for this result is the interaction of tax policy with the underlying demand structure that allows mark-ups to be endogenous.

We define the ratio of a firm's tax payments relative to pre-tax profits (effective tax rate):

$$
\Gamma(c)=\frac{\text { tax payments }}{\text { pre-tax profits }}=\frac{t(p(c)-\beta c) q(c)}{(p(c)-c) q(c)} \text {. }
$$


After inserting the equilibrium price Eq. (7), we obtain:

$$
\Gamma(c)=\frac{t\left(\Psi \frac{c_{D}+c}{2}-\beta c\right)}{\left(\Psi \frac{c_{D}+c}{2}-c\right)} .
$$

Taking the derivative of Eq. (18) with respect to the cost parameter $c$ leads to:

$$
\frac{\partial \Gamma(c)}{\partial c}=\frac{t \Psi c_{D}(1-\beta)}{2\left(\Psi \frac{c_{D}+c}{2}-c\right)^{2}}>0 .
$$

Proposition 1 In a model with linear demand and partial deductibility of production costs, the ratio of tax payments to pre-tax profits (effective tax rate) is lower for larger firms, whereas this ratio is constant across firms with CES-demand.

Proof. See Appendix.

Proposition 1 shows that the relationship between production costs and relative tax payments is positive if there is both imperfect cost pass-through into prices and partial tax deductibility of production costs. If one requirement is not met, the ratio is constant and independent of production costs. With linear demand, there is imperfect cost pass-through. Firms with higher marginal costs $c$ charge higher prices and earn lower mark-ups. If $\beta<1$, only a fraction of this cost disadvantage is deductible, such that the ratio $\Gamma(c)$ increases in production $\operatorname{costs} c$. Only with full deductibility $(\beta=1)$, the effective tax rate is constant across firms. In the Appendix, we show that with CES-demand, the ratio $\Gamma$ does not depend on firm size. In this case, prices are set as a constant mark-up over marginal production costs and there is perfect pass-through of taxes into consumer prices.

Empirical studies find evidence for both a positive and a negative relation between firm size and effective tax rates (Belz et al. , 2018). Note that our framework is flexible enough to integrate both views. If production costs are subsidized (i.e. $\beta>1$ ) the result in Proposition 1 is reversed and our model predicts a positive relationship between firm size and the effective tax rate. Again, this result would not emerge in a CES framework.

One alternative explanation for the negative relationship between firm size and the effective tax rate is profit shifting of multinationals. The latter have been found to be larger and more productive than domestic firms (Helpman et al. , 2004; Yeaple, 2009) and use tax havens more extensively (Desai et al. , 2006). In Krautheim \& Schmidt-Eisenlohr (2011) the use of tax havens is associated with additional fixed costs such that only more productive producers shift profits abroad. However, we show that in a framework with endogenous mark-ups, the more productive firms pay lower effective tax rates even without profit shifting. We argue, that this additional channel should be taken into account when evaluating 
the implications of tax policy across countries because otherwise the effects of tax evasion would be overstressed. A similar argument applies to the evaluation of lobbying activities.

The relationship between effective tax rates and firm size is also affected by economy-wide shocks. As discussed in the trade literature, we can evaluate these shocks through changes in the cost cutoff $c_{D}$ as a sufficient statistic. Melitz \& Ottaviano (2008) show that an increase in market size $L$ has the same implications as trade liberalization and reduces the cost cutoff $c_{D}$. Both shocks increase expected profits which induces firm entry and hence, existing firms face stronger competition. As a consequence, high cost firms have to exit the market. As a second shock, we consider an increase in the tax factor $\Psi$, which could be caused by an increase in the tax rate $t$ or a decrease in the share of deductible costs $\beta$. A higher tax factor especially hurts high cost firms and reduces the cost cutoff $c_{D}$ as shown in Eq. (15). ${ }^{10}$

A change in the cost cutoff affects the effective tax rate as follows:

$$
\frac{\partial \Gamma(c)}{\partial c_{D}}=-\frac{\Psi c t(1-\beta)}{2\left(\Psi \frac{c_{D}+c}{2}-c\right)^{2}}<0 .
$$

We also show that this change becomes stronger for high-cost firms as:

$$
\frac{\partial \Gamma(c)}{\partial c_{D} \partial c}=-\frac{t \Psi(1-\beta)\left(\Psi^{2}\left(c_{D}^{2}-c^{2}\right)+4(\Psi-1) c^{2}\right)}{8\left(\Psi \frac{c_{D}+c}{2}-c\right)^{4}}<0 .
$$

We summarize our results as follows:

Proposition 2 In a model with linear demand and partial deductibility of production costs, the ratio of tax payments to pre-tax profits increases with trade liberalization and the market size. This increase is stronger for smaller firms.

In the public debate, globalization is perceived as an important driving force for the heterogeneity in effective tax rates across firms as it facilitates profit-shifting of large companies. We provide a new explanation how globalization increases the difference in relative tax payments across firms, even in the absence of profit shifting and lobbying activities. Trade liberalization increases the toughness of competition which reduces mark-ups especially for smaller firms. This channel has been extensively studied in the recent trade literature, but has received less attention in the public finance literature. Accounting for these competition effects is crucial to evaluate the implications of profit shifting and tax evasion.

\footnotetext{
${ }^{10}$ The derivative of Eq. (14) with respect to market size $L$ is given by: $\frac{d c_{D}}{d L}=-\frac{1}{2+k} \frac{\gamma \phi}{\Psi c_{D}^{1+k}}<0$.
} 


\section{Conclusion}

Our model has shown that the negative relationship between relative tax payments and firm size is not necessarily an indication for profit shifting or the use of tax havens. We argue that a tax system which allows for a partial deductibility of production costs in combination with heterogeneous firms could generate such a result when mark-ups are endogenous. This should be taken into account by policy makers aiming at reducing the use of tax havens as it is not clear to what extent the negative relation between tax payments and firm size is due to such activities. To evaluate the costs and benefits of policy measures, it is important to disentangle the different channels which cause the comparatively low tax payments of large companies. In this context, controlling for competition effects of tax policy is a challenge for future empirical work.

Moreover, we have shown an additional channel how globalization reinforces the heterogeneity in effective tax burdens across firms. This implies that globalization does not only facilitate profit shifting as shown by the existing literature, but also leads to pro-competitive effects which interact with tax policy.

Our model provides a rationale for differences of effective tax rates across heterogeneous firms in a very tractable way. This framework could be extended in several dimensions related to optimal tax policy, tax competition, and country asymmetries. We hope that our analysis encourages future work on the interaction of tax policy and pro-competitive effects. 


\section{References}

Baldwin, Richard, \& Okubo, Toshihiro. 2009. Tax Reform, Delocation, and Heterogeneous Firms. The Scandinavian Journal of Economics, 111(4), 741-764.

Bauer, Christian, Davies, Ronald B, \& Haufler, Andreas. 2014. Economic Integration and the Optimal Corporate Tax Structure with Heterogeneous Firms. Journal of Public Economics, 110, 42-56.

Bauer, Christian J., \& Langenmayr, Dominika. 2013. Sorting into Outsourcing: Are Profits Taxed at a Gorilla's Arm's Length? Journal of International Economics, 90(2), 326-336.

Bellone, Flora, Musso, Patrick, Nesta, Lionel, \& Warzynski, Frederic. 2016. International Trade and Firm-Level Markups when Location and Quality Matter. Journal of Economic Geography, 16(1), 67-91.

Belz, Thomas, von Hagen, Dominik, \& Steffens, Christian. 2018. Taxes and Firm Size: Political Cost or Political Power? A Meta-Regression Analysis. SSRN Electronic Journal.

Bombardini, Matilde. 2008. Firm Heterogeneity and Lobby Participation. Journal of International Economics, 75(2), 329-348.

Davies, Ronald B., \& Eckel, Carsten. 2010. Tax Competition for Heterogeneous Firms with Endogenous Entry. American Economic Journal: Economic Policy, 2(1), 77-102.

Davies, Ronald B, Martin, Julien, Parenti, Mathieu, \& Toubal, Farid. 2018. Knocking on Tax Havens Door: Multinational Firms and Transfer Pricing. Review of Economics and Statistics, 100(1), 120-134.

De Loecker, Jan, \& Warzynski, Frederic. 2012. Markups and Firm-Level Export Status. American Economic Review, 102(6), 2437-71.

Desai, Mihir A, Foley, C Fritz, \& Hines Jr, James R. 2006. The Demand for Tax Haven Operations. Journal of Public Economics, 90(3), 513-531.

Egger, Peter H., Strecker, Nora M., \& Zoller-Rydzek, Benedikt. 2018. Estimating Bargainingrelated Tax Advantages of Multinational Firms. Tech. rept.

Gumpert, Anna, Hines Jr, James R, \& Schnitzer, Monika. 2016. Multinational Firms and Tax Havens. Review of Economics and Statistics, 98(4), 713-727. 
Haufler, Andreas, \& Langenmayr, Dominika. 2015. How Does Firm Heterogeneity Affect International Tax Policy? DICE Report, 13(2), 57.

Haufler, Andreas, \& Stähler, Frank. 2013. Tax Competition in a Simple Model with Heterogeneous Firms: How Larger Markets Reduce Profit Taxes. International Economic Review, 54(2), 665-692.

Helpman, Elhanan, Melitz, Marc J, \& Yeaple, Stephen R. 2004. Export versus FDI with heterogeneous firms. American Economic Review, 94(1), 300-316.

Krautheim, Sebastian, \& Schmidt-Eisenlohr, Tim. 2011. Heterogeneous Firms, Profit Shifting FDI and International Tax Competition. Journal of Public Economics, 95(1), 122-133.

Melitz, Marc J. 2003. The Impact of Trade on Intra-Industry Reallocations and Aggregate Industry Productivity. Econometrica, 71(6), 1695-1725.

Melitz, Marc J., \& Ottaviano, Gianmarco I. P. 2008. Market Size, Trade, and Productivity. Review of Economic Studies, 75(1), 295-316.

Mrázová, Monika, \& Neary, J. Peter. 2017. Not So Demanding: Demand Structure and Firm Behavior. American Economic Review, 107(12), 3835-74.

Ottaviano, Gianmarco, Tabuchi, Takatoshi, \& Thisse, Jacques F. 2002. Agglomeration and Trade Revisited. International Economic Review, 43(2), 409-435.

Ottaviano, Gianmarco I.P., \& van Ypersele, Tanguy. 2005. Market Size and Tax Competition. Journal of International Economics, 67(1), 25-46.

Richter, Brian Kelleher, Samphantharak, Krislert, \& Timmons, Jeffrey F. 2009. Lobbying and Taxes. American Journal of Political Science, 53(4), 893-909.

Weyl, E. Glen, \& Fabinger, Michal. 2013. Pass-Through as an Economic Tool: Principles of Incidence under Imperfect Competition. Journal of Political Economy, 121(3), 528-583.

Yeaple, Stephen Ross. 2009. Firm heterogeneity and the structure of US multinational activity. Journal of International Economics, 78(2), 206-215. 


\section{Appendix: Model with CES preferences}

In this section, we show that our main result does not emerge in a CES framework. Suppose that preferences are given by:

$$
Q=\left[\int_{i \in \Omega} q_{i}^{\frac{\sigma-1}{\sigma}} d i\right]^{\frac{\sigma}{\sigma-1}},
$$

whereas $\Omega$ is the set of differentiated varieties and $\sigma>1$ denotes the constant elasticity of substitution across varieties. Consumer maximization yields the following demand:

$$
q(i)=Q\left(\frac{p(i)}{P}\right)^{-\sigma}
$$

whereas $P$ denotes the aggregate price index. Firms maximize profits in Eq. (6) subject to demand (23), which leads to the optimal price

$$
p(c)=\frac{\sigma}{\sigma-1} \Psi c,
$$

which is a constant mark-up over effective marginal production costs. Computing the ratio of tax payments relative to pre-tax profits as in Eq. (17), leads to:

$$
\Gamma(c)_{C E S}=\frac{t(p(c)-\beta c)}{p(c)-c}=t \frac{\sigma(\Psi-\beta)+\beta}{\sigma(\Psi-1)+1} .
$$

Hence, in a CES framework the ratio of tax payments relative to pre-tax profits is independent of firm productivity in contrast to Proposition 1. Additionally, it does not depend on general equilibrium effects and thus is not able to explain our result in Proposition 2. 